\title{
Dynamic Response of Pultruded Glass-Graphite/Epoxy Hybrid Composites Subjected to Transverse High Strain-Rate Compression Loading
}

\author{
Mohammad Afrough*, Tejas S. Pandya, Seyed Soheil Daryadel, Prabhakar Raju Mantena \\ Composite Structures and Nano-Engineering Research, Department of Mechanical Engineering, University of \\ Mississippi, Oxford, USA \\ Email: *mafrough@go.olemiss.edu
}

Received 18 September 2015; accepted 14 November 2015; published 17 November 2015

Copyright (C) 2015 by authors and Scientific Research Publishing Inc.

This work is licensed under the Creative Commons Attribution International License (CC BY).

http://creativecommons.org/licenses/by/4.0/

(c) (i) Open Access

\begin{abstract}
In a previous study, the energy absorption and dynamic response of different combinations of cylindrical fiber-reinforced pultruded hybrid composite samples made of unidirectional glass and graphite fiber/epoxy, were investigated under longitudinal compression loading. It was found that placing glass fibers in the inner core of composites resulted in a higher ultimate compressive strength and specific energy absorption. In this study, the dynamic responses of pultruded glassgraphite/epoxy hybrid specimens with rectangular cross-section subjected to transverse compression loading are reported. Crack initiation and propagation was monitored using a high-speed video camera, and the effects of hybridization were analyzed. It was found that the location of glass or graphite fibers inside the pultruded composites has no significant effect on the ultimate compressive strength under such transverse compression loading. The energy absorption in all the hybrid specimens was almost identical. Graphite/epoxy composite showed higher specific energy absorption due to its lower density, and glass/epoxy composite had the lowest specific energy absorption.
\end{abstract}

\section{Keywords}

Pultruded Composites, High Strain-Rate Compression Loading, SHPB, Energy Absorption, Transverse Loadings

\footnotetext{
*Corresponding author.
} 


\section{Introduction}

Composites are utilized because they have desired properties which cannot be attained by other types of constituent materials. Fibrous composites, including reinforcing fibers embedded in a matrix material, are commonly used in different applications. Fiber-reinforced composite materials present different features in terms of stiffness, specific strength, deformation etc. Their usage encompasses a wide range of applications in automotive, aerospace and marine.

The two most common reinforcing fibers are glass and graphite. Glass fibers have high tensile strength and low tensile modulus. On the other hand, graphite fibers possess very high tensile modulus, low weight and low impact resistance. A number of investigations have been carried out on pultruded composites [1]-[13]. Their results illustrate that hybridization with different percentages of glass and graphite within the same epoxy matrix has a significant effect on the mechanical properties.

In many applications, composite materials are subjected to dynamic loading, which is produced by vibration or wave propagation [14]. Therefore, it is necessary to investigate the strain rate sensitivity, failure modes and other behaviors under dynamic loading. Several studies have been performed on strain rate sensitivity [15]-[17]. Ochola et al. [18] tested a glass fiber reinforced polymer at different strain rates. The results show that the value of mean ultimate compressive stress for this composite increased by $20.9 \%$ as the strain rate is increased from $10^{-3}$ to $450 \mathrm{~s}^{-1}$. Various set-ups like drop-weight and Split Hopkinson Pressure Bar (SHPB) have been used [19] [20].

Furthermore, direction of loading and fiber orientation play an important role in dynamic behavior of composite materials. Yokoyama et al. [21] investigated cubic specimens of carbon/epoxy laminates behavior in all three principal material directions under high strain rate compression test and discussed the failure mechanism of composites. They show that by increasing strain rate, while the compression is along the fiber direction, ultimate strength increases, and energy absorbed up to failure strain decreases. In a previous investigation by the authors [22], the energy absorption and dynamic response of different combinations of glass and graphite pultruded composites under longitudinal compression loading was studied. It was found that locating glass fibers in the inner core raises the ultimate compressive strength and results in better dynamic behavior of the composite. Since there are many applications where loads are applied in transverse direction, optimization of pultruded composite materials from this point of view is necessitated.

The purpose of this study is to analyze the dynamic behavior and energy absorption of pultruded glass-graphite/epoxy hybrid composites by applying transverse compression load at high strain-rate. A modified SHPB test system has been used for producing dynamic load. Additionally, a high-speed camera was deployed to record the events and monitor crack initiation, propagation and failure of samples during the tests.

\section{Specimen Details}

Samples for SHPB test were cut from long rectangular cross-section composite beams manufactured by the pultrusion process (Pulstar 804 machine). Glass and graphite fibers were used for reinforcement, while volume fraction of epoxy was maintained at $40 \%$. The graphite fibers were AS4W-12K (Hercules), the glass fibers were E-Glass (PPG 2001, \#12), and the epoxy was EPON 862/W/537 (Shell Chemical Company, USA). All the SHPB test samples were cut precisely in $6.6 \mathrm{~mm} \times 6.6 \mathrm{~mm}$ section from $3.3 \mathrm{~mm}$ thick long rectangular beams (Figure 1).

The six fiber combinations with layup sequence for hybrid composite test samples are shown in Table 1. Reference [23] describes more details of the manufacturing process for these pultruded beam samples. The measured bulk densities of the specimens are shown in Table 2.

\section{Experimental Technique}

The high strain-rate testing was carried out using a modified SHPB located at the Blast and Impact Dynamics Laboratory, University of Mississippi. A schematic of SHPB set-up is shown in Figure 2. It consists of a striker bar, a strain gaged incident/input bar and a transmitter/output bar. The bars are made of maraging steel. Specimens are sandwiched between the incident and transmission bars. A copper pulse shaper was applied to attain a triangular incident pulse. Petroleum jelly was used to place specimen between the incident and transmitter bars, and also to avoid friction and shear effects on the samples during testing. 


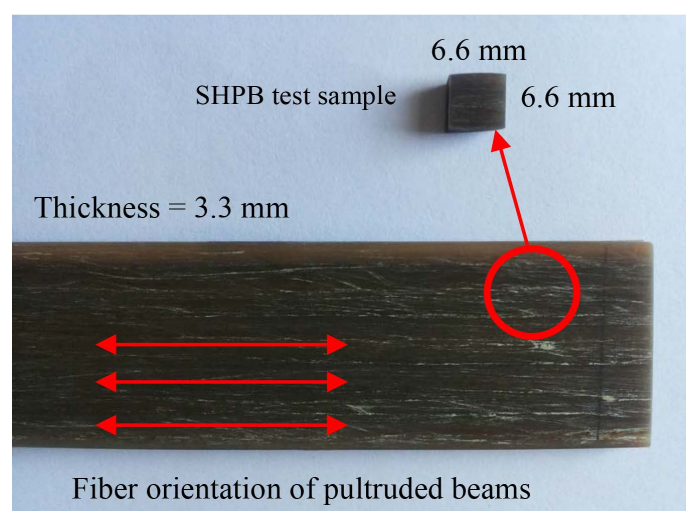

Figure 1. Dimensions of test samples cut from rectangular cross-section pultruded beams.

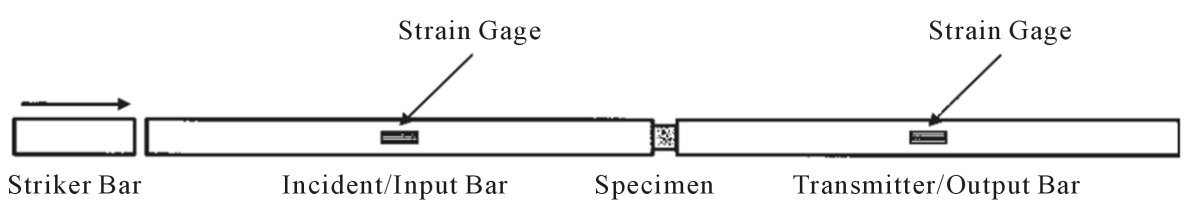

Figure 2. Schematic of a Split Hopkinson Pressure bar [20].

Table 1. Fiber combinations with layup sequence for hybrid composites [23].

\begin{tabular}{|c|c|c|c|c|}
\hline \multirow[b]{2}{*}{ Specimen ID } & \multicolumn{2}{|c|}{ Fiber Volume Fraction (\%) } & \multirow{2}{*}{$\begin{array}{c}\text { Resin System (\%) } \\
\text { EPON } 862 \\
\text { Resin System }\end{array}$} & \multirow{2}{*}{$\begin{array}{l}\text { Cross } \\
\text { Section }\end{array}$} \\
\hline & $\begin{array}{l}\text { Graphite } \\
\text { (AS4W-12) }\end{array}$ & $\begin{array}{c}\text { Glass } \\
\text { (PPG 2001, \#12) }\end{array}$ & & \\
\hline CFMIX01 & 60 & 0 & 40 & \\
\hline CFMIX02 & 0 & 60 & 40 & \\
\hline CFMIX03 & 20 & $20+20$ & 40 & \\
\hline CFMIX04 & 30 & $15+15$ & 40 & \\
\hline CFMIX05 & $20+20$ & 20 & 40 & \\
\hline CFMIX06 & $15+15$ & 30 & 40 & \\
\hline
\end{tabular}

Table 2. Measured average bulk densities of the pultruded hybrid specimens.

\begin{tabular}{cccc}
\hline & CFMIX01 & CFMIX02 & CFMIX03 \\
Density $\left(\mathbf{k g} / \mathbf{m}^{3}\right)$ & 1569 & 1924 & 1807 \\
& CFMIX04 & CFMIX05 & CFMIX06 \\
& 1809 & 1749 & 1784 \\
\hline
\end{tabular}

A high-speed video camera (HyperVision HPV-2, Shimadzu Corporation, Japan) was employed to record the events and monitor the crack initiation, propagation and failure of samples during the SHPB compression loading tests. One hundred and two frames of each event were recorded at a frame rate of 500,000 fps. Two $1000 \mathrm{~W}$ strobes were used to provide the required lighting.

\section{Results and Discussion}

Six combinations of pultruded glass-graphite/epoxy hybrid samples were tested under transverse compression 
loading. Figure 3 shows typical stress wave pulses including incident, reflected and transmitted pulses. For validating the dynamic equilibrium condition, a test specimen must be in force equilibrium [22]. The stresses in both interfaces of each specimen were calculated to ensure that equilibrium was attained (Figure 4).

Five samples were tested for each combination at an average strain rate of $800 \mathrm{~s}^{-1}$. Figure 5 shows typical stress-strain behavior for all the combinations. All curves are plotted until shattering point of each specimen, with high-speed photography utilized for capturing this moment. They are essentially coincident with each other until ultimate compressive strength with all of them possessing equal initial stiffness. This synchronization appears to be from matrix dominant response for these pultruded composites, with compression load applied in the transverse direction.

Figure 6 illustrates the average ultimate compressive strength for six specimens of each combination. CFMIX01 with $60 \%$ graphite possess the highest ultimate compressive strength and CFMIX02 with $60 \%$ glass has the lowest. The compressive strength of hybrid with $40 \%$ graphite in the outer layer and $20 \%$ glass in the

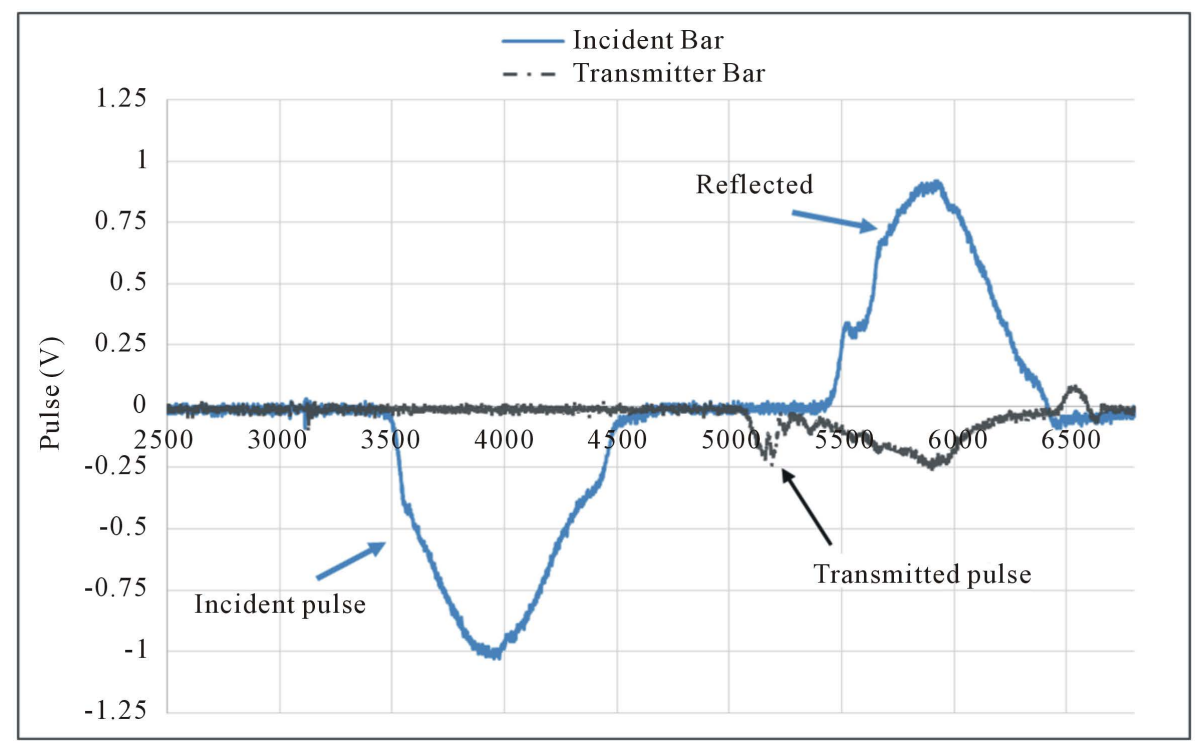

Figure 3. Typical incident, reflected and transmitted pulses from SHPB test of a pultruded hybrid composite sample.

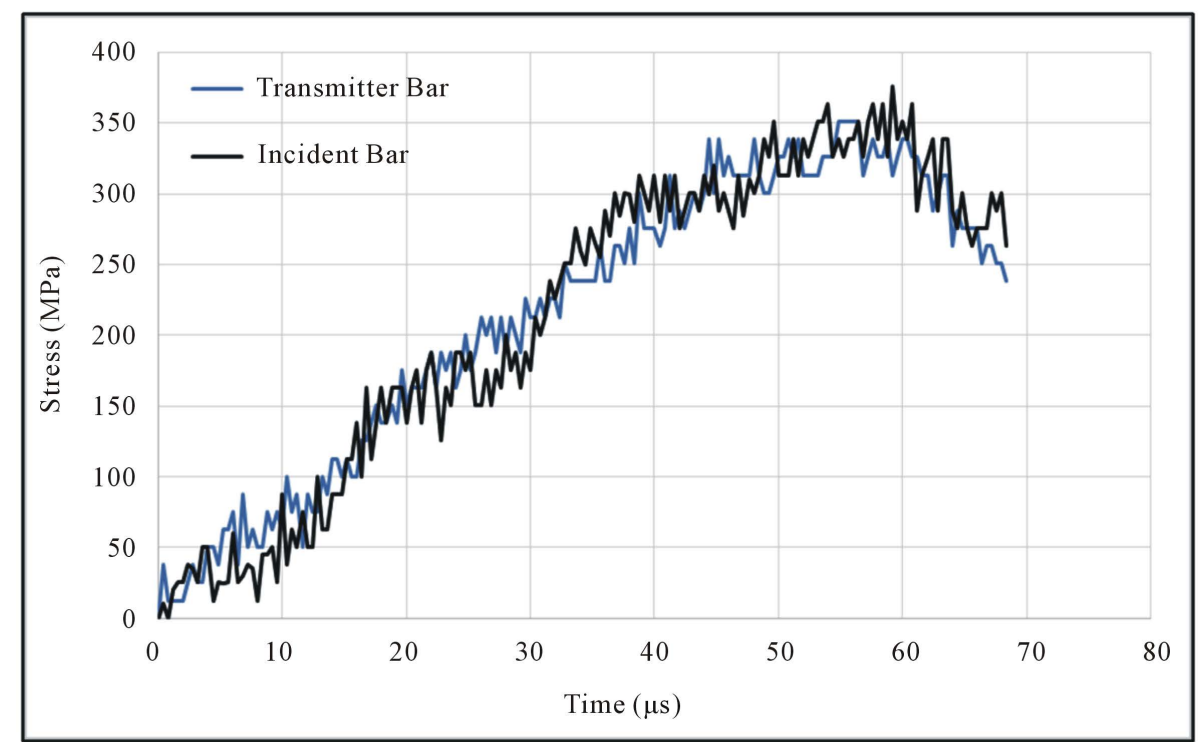

Figure 4. Validation of stress equilibrium for tested pultruded hybrid composite sample. 


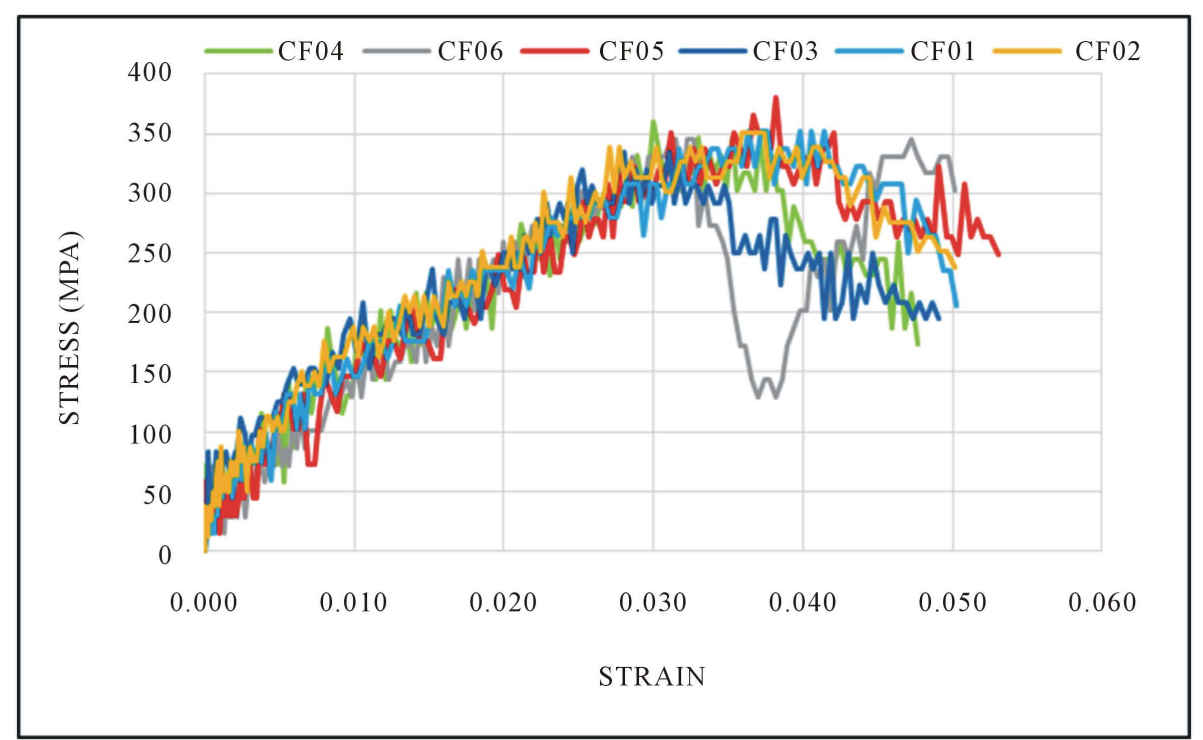

Figure 5. Typical stress-strain curve for all hybrids tested by SHPB transverse compression loading.

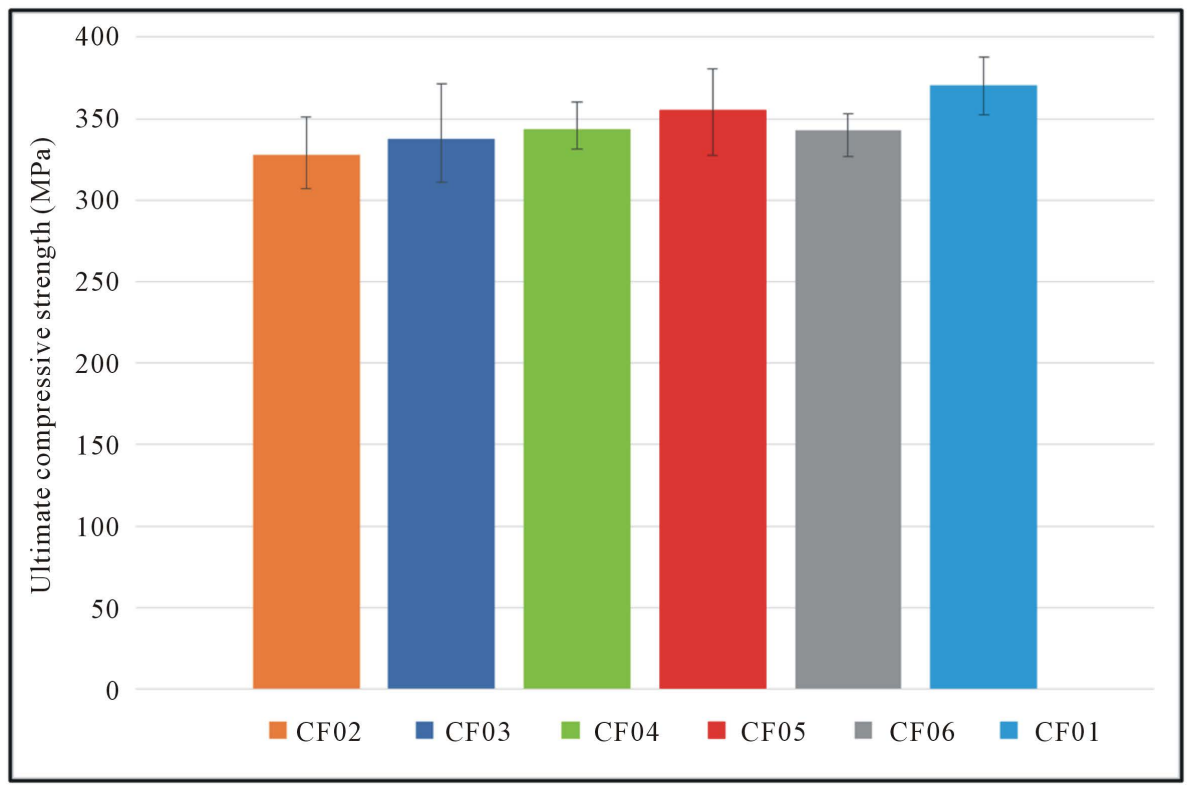

Figure 6. Ultimate compressive strength (MPa) for all hybrids tested by SHPB transverse compression loading.

core, CFMIX05, is slightly nearer to graphite/epoxy. The small difference between the highest and lowest ultimate compressive strength demonstrates that using different portions of glass and graphite fibers does not dramatically change the compressive strength under transverse compression dynamic loading. This small difference results from the stronger bond between graphite fiber and epoxy matrix compared to the bond between glass fiber and epoxy matrix, perhaps due to the sizing of graphite fibers for improving adhesion during pultrusion manufacturing. As can be seen in Figure 7, graphite fibers (Figure 7(a)), have mostly disintegrated after the compression event while glass fibers (Figure 7(b)), remained almost intact.

As can be seen in Figure 5, all the specimens absorbed almost equivalent amounts of energy (integration of area under stress-strain curve) during the dynamic compression tests, with specimens having greater volume fraction of graphite fibers absorbing marginally more energy. CF06 samples showed a distinct drop towards the 


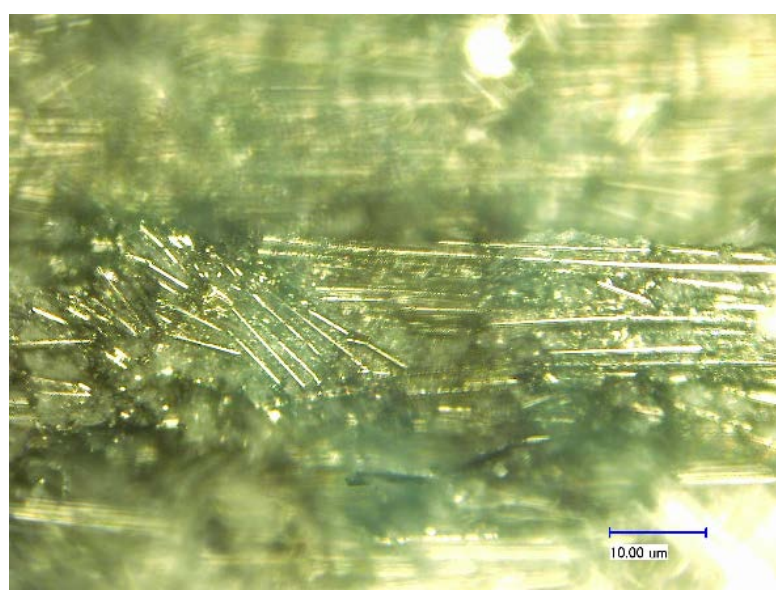

(a)

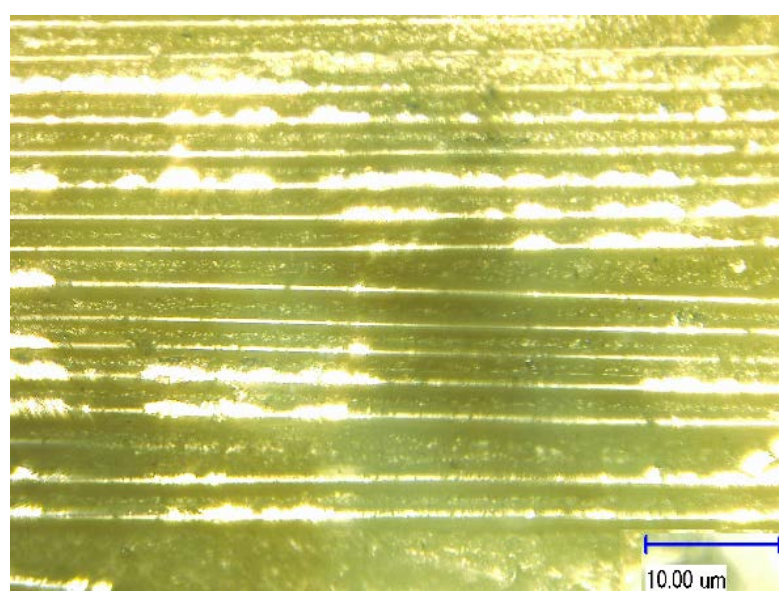

(b)

Figure 7. Micrograph view of specimens after transverse compression event (500×). (a) Graphite fibers; and (b) Glass fibers.

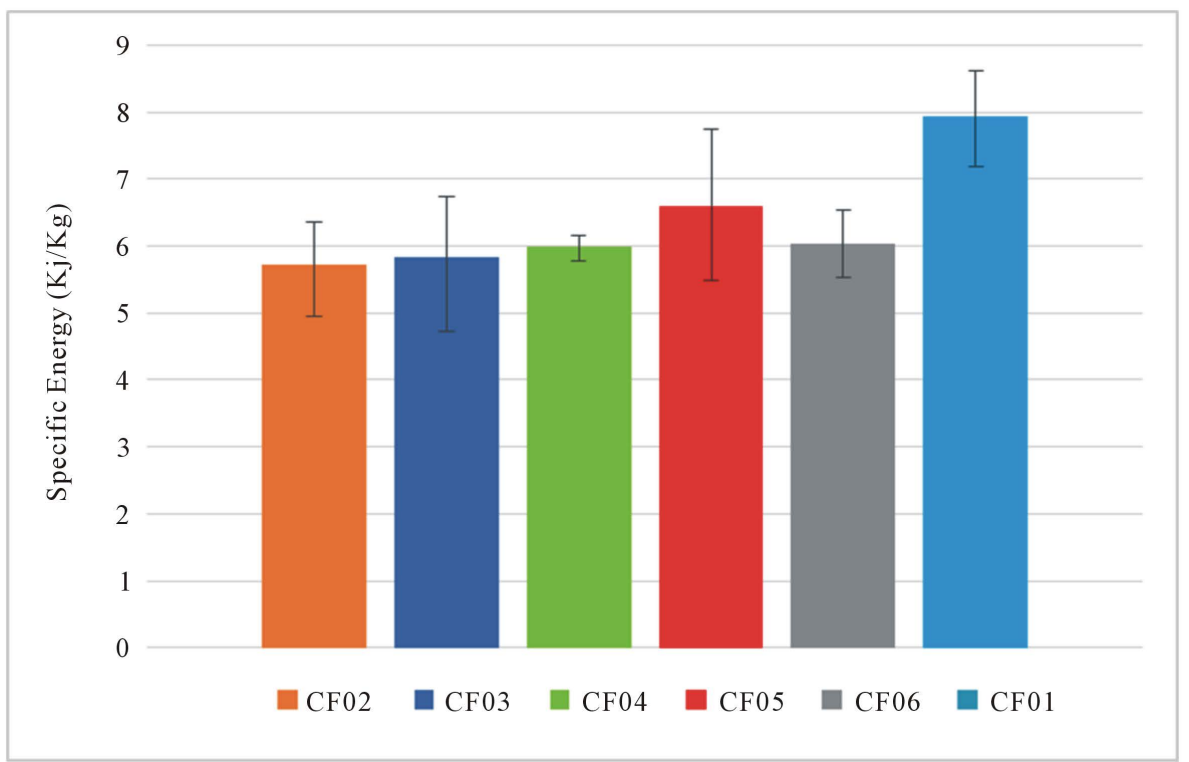

Figure 8. Specific energy absorption for all hybrid specimens tested by SHPB under transverse compression loading.

end of the compressive event, perhaps due to the larger portion of glass fibers located in the central region. However, the specific energy absorption (energy absorbed per unit mass) for each specimen is distinct due to their different densities (Figure 8). As shown in Table 2, specimens with more graphite fibers have lower density, which resulted in higher specific energy absorption. Specimens with 60\% graphite (CFMIX01) and 40\% graphite (CFMIX05) show the highest specific energy absorption; while 60\% glass (CFMIX02) exhibits the lowest specific energy absorption.

As mentioned, a high-speed video camera was deployed to monitor the crack initiation, propagation and failure of samples during the SHPB compression loading tests. For these samples, the event (from time zero to crack initiation of specimen) takes $55 \mu \mathrm{s}-75 \mu \mathrm{s}$. Four stages of specimen CFMIX05 deformation are shown in Figure 9. The stress versus time history of this specimen is depicted in Figure 10. Three red dots show starting point, ultimate strength point and crack initiation point. The maximum load (ultimate strength) occurs at $51 \mu \mathrm{s}$ and crack initiates at $66 \mu \mathrm{s}$. The image at $79 \mu \mathrm{s}$ shows that the fiber glass in the specimen core detaches from epoxy matrix. The results indicate that the entire sample has not been completely damaged at the peak stress. It should be noted that the compression load is applied transverse to the fiber direction, i.e., load is perpendicular to the fiber orientation for each of the tested hybrid composites. 

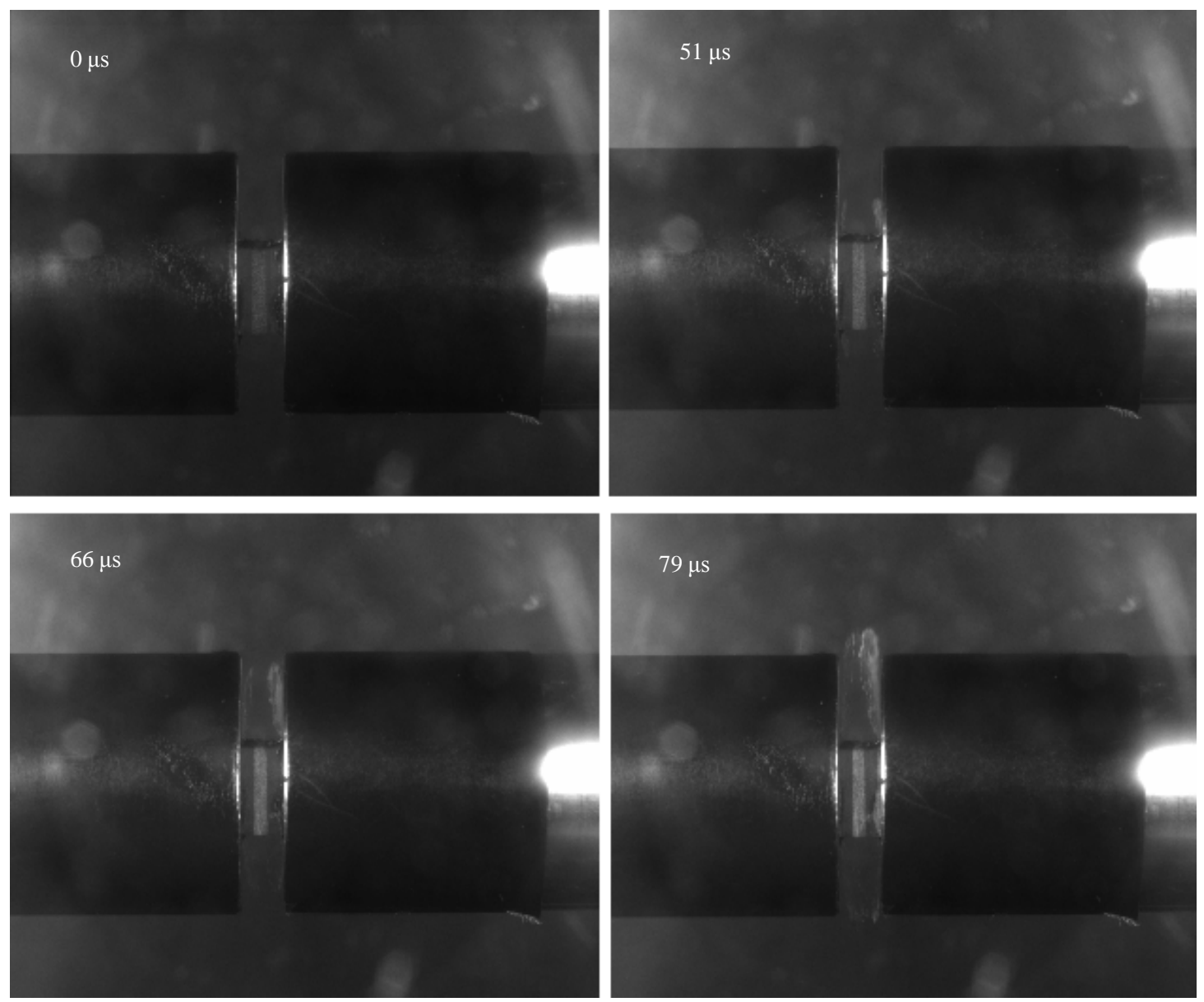

Figure 9. Four stages of specimen CFMIX05 deformation under transverse compression at different times.

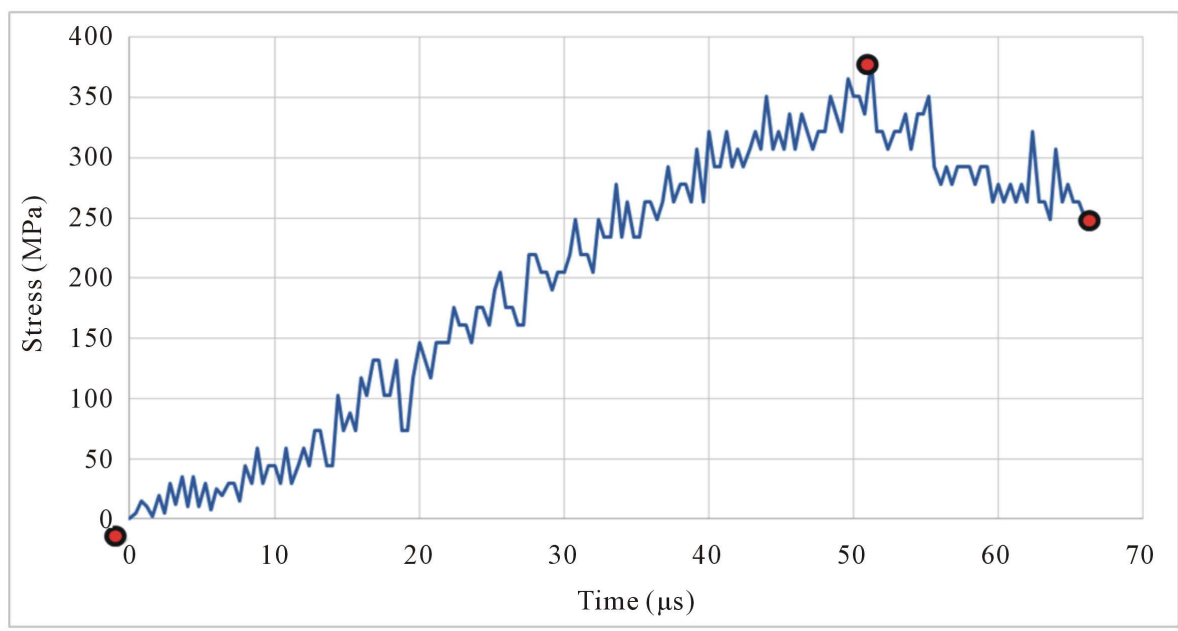

Figure 10. Stress versus time history of CFMIX05 under transverse compression loading. Three red dots show st.

A comparison between this study and previous investigation conducted by the authors on longitudinal compressive loading [22] shows dramatic difference in the dynamic response of graphite-glass/epoxy pultruded hybrids under transverse and longitudinal loading conditions. Figure 11 and Figure 12 show the ultimate compressive strength and average specific energy of cylindrical hybrid combinations where GL60, GR60, GL30 and 


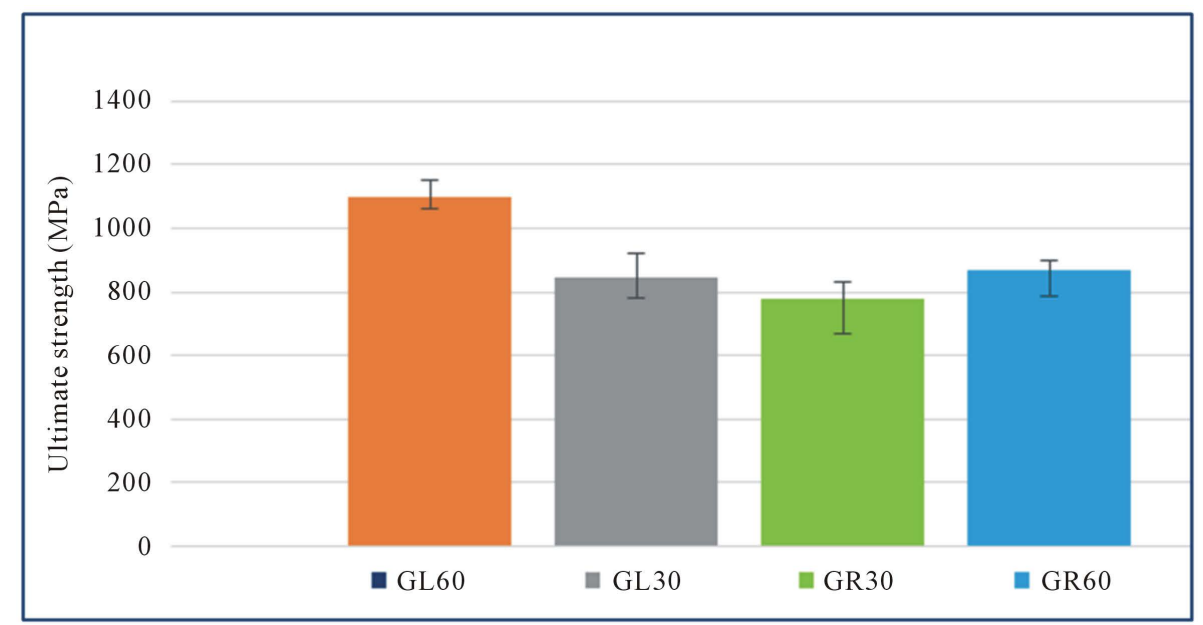

Figure 11. Ultimate compressive strength for different combinations of pultruded hybrids under longitudinal compression loading [22].

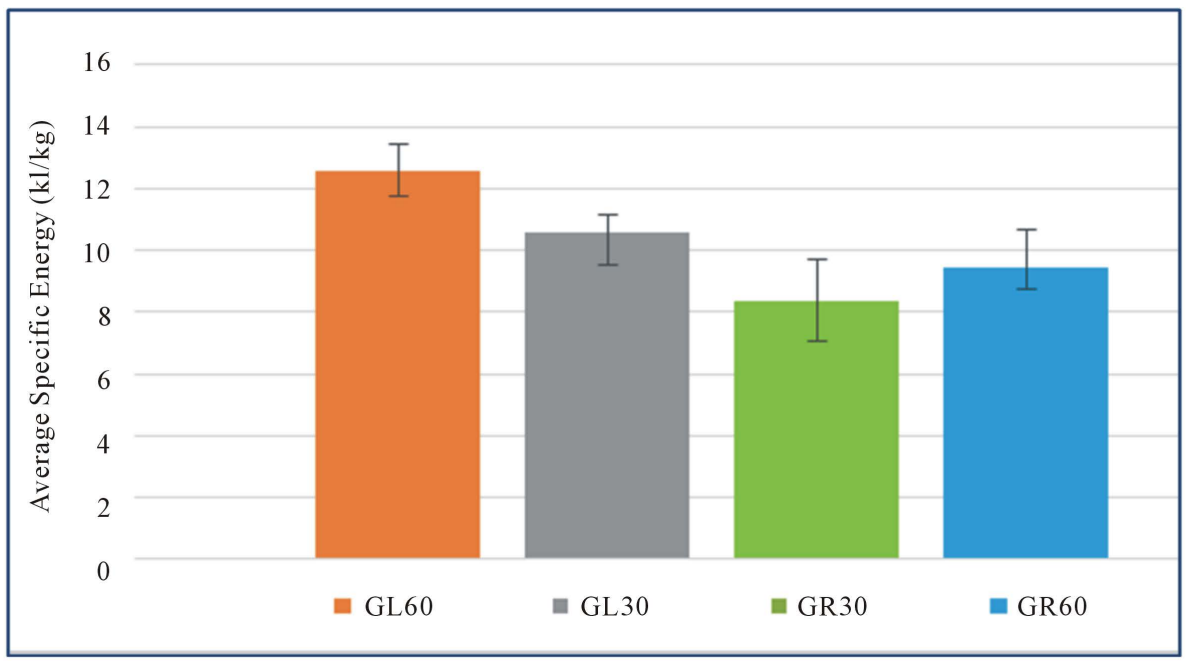

Figure 12. Average specific energy absorption for different combinations of pultruded hybrids under longitudinal compression loading [22].

GR30 have respectively similar hybrid combinations of CF02, CF01, CF06 and CF04 used in this study. It is apparent that under transverse compression dynamic loading, ultimate compressive strength of graphite-glass/ epoxy pultruded hybrids is about one-third of that under longitudinal compression dynamic loading. On the other hand, specific energy absorption under longitudinal compression loading shows an opposite trend to the response under transverse compression loading.

\section{Conclusion}

In this investigation, six combinations of pultruded glass-graphite/epoxy hybrids have been experimentally studied under transverse high strain-rate compression loading, using a modified SHPB. It was observed that failure of specimens loaded along transverse direction was dominated by matrix failure. It was also observed that $60 \%$ graphite (CFMIX01) has the highest ultimate compressive strength. The ultimate compressive strength was also marginally greater with higher percentage of graphite. This marginal difference results from the stronger bond between graphite fiber and epoxy compared to that between glass fiber and epoxy, perhaps due to the sizing of graphite fibers for better adhesion. Location of glass or graphite fibers inside the pultruded composites had no significant effect on the ultimate compressive strength under transverse compression dynamic loading. While all 
specimens absorbed almost equivalent amount of energy, the graphite/epoxy samples demonstrated significantly higher specific energy absorption compared to the other combinations. This was due to its lower density, while glass/epoxy showed the lowest specific energy absorption. Moreover, comparison between this study and a previous investigation conducted by the authors showed significant differences in the response under longitudinal and transverse dynamic loading.

\section{Acknowledgements}

The authors wish to acknowledge funding received from US Army Research Office-DURIP Grant \# W911NF13-1-0248 for the high-speed digital cameras used in this research. The authors would also like to thank Mr. P. Matthew Lowe, for his help with sample preparation.

\section{References}

[1] Swaminathan, R. and Raju Mantena, P. (2003) Axial Loading and Buckling Response Characteristics of Pultruded Hybrid Glass-Graphite/Epoxy Composites. Journal of Reinforced Plastics and Composites, 22.

[2] Nori, C.V., Raju Mantena, P. and McCarty, T.A. (1996) Experimental and Finite Element Analysis of Pultruded GlassGraphite/Epoxy Hybrids in the Axial and Flexural Modes of Vibration. Journal of Composite Materials, 30. http://dx.doi.org/10.1177/002199839603001803

[3] Shokrieh, M.M. and Omidi, M.J. (2011) Investigating the Transverse Behavior of Glass-Epoxy Composites under Intermediate Strain Rates. Journal of Composite Structures, 93, 690-696. http://dx.doi.org/10.1016/j.compstruct.2010.08.010

[4] Hosur, M.V., Adya, M., Jeelani, S., Vaidya, U.K. and Dutta, P.K. (2004) Experimental Studies on the High Strain Rate Compression Response of Woven Graphite/Epoxy Composites at Room and Elevated Temperatures. Journal of Reinforced Plastics and Composites, 23, 491-514. http://dx.doi.org/10.1177/0731684404032019

[5] Vaughan, J.G., Roux, J.A. and Mantena, P.R. (1992) Characterization of Mechanical and Thermal Properties of Advanced Composite Pultrusion. Proceedings of the 1992 NSF Design and Manufacturing Systems Conference, 11411145.

[6] Mantena, P.R., Vaughan, J.G., Donti, R.P. and Kowsika, M.V. (1992) Influence of Process Variables on the Dynamic Characteristics of Pultruded Graphite-Epoxy Composites. Vibro-Acoustic Characterization of Materials and Structures, ASME, 14, 147-154.

[7] Almagableh, A., Gupta, S., Raju Mantena, P. and Al-Ostaz, A. (2008) Dynamic Mechanical Analysis of Graphite Platelets and Nanoclay Reinforced Vinyl Ester, and MWCNT Reinforced Nylon 6.6 Nanocomposites. Proceedings of the 2008 SAMPE Fall Technical Conference, (Paper \# 034 on CD) ROM, Memphis, 8-11 September 2008.

[8] Jadhav, P., Raju Mantena, P. and Gibson, R.F. (2006) Energy Absorption and Impact Damage Evaluation of GridStiffened Composite Panels under Transverse Loading. Composites Engineering, Part B, 37, 191-199. http://dx.doi.org/10.1016/j.compositesb.2005.05.017

[9] Kowsika, M., Raju Mantena, P. and Balasubramniam, K. (2002) Energy Absorption and Dissipation Characteristics of Pultruded Glass-Graphite/Epoxy Hybrid Composite Beams. Journal of Thermoplastic Composite Materials, 15. http://dx.doi.org/10.1177/0892705702015003453

[10] Raju Mantena, P., Mann, R. and Nori, C.V. (2003) Low Velocity Impact Response and Dynamic Characteristics of Glass-Resin Composites. Journal of Reinforced Plastics and Composites, 20, 513-534.

[11] Barpanda, D. and Mantena, P.R. (1998) Effects of Hybridization on the Creep and Stress Relaxation Characteristics of Pultruded Composites. Journal of Reinforced Plastics and Composites, 17, 234-249.

[12] Barpanda, D. and Mantena, P.R. (1996) Dynamic Mechanical Analysis of Pultruded Glass-Graphite/Epoxy Hybrid Composites at Elevated Temperatures. Journal of Reinforced Plastics and Composites, 15, 497-532.

[13] Kumar, S. and Mantena, P.R. (1996) Dynamic and Static Torsional Characterization of Pultruded Hybrid Cylindrical Composite Rods. Journal of Composite Materials, 30, 918-932. http://dx.doi.org/10.1177/002199839603000804

[14] Gibson, R.F. (2007) Principles of Composite Material Mechanics. 2nd Edition, CRC Press, Boca Raton.

[15] Sierakowski, R.L. (1997) Strain Rate Effects in Composites. Applied Mechanics Reviews, 50, 741-761.

[16] Hamouda, A.M.S. and Hashmi, M.S.J. (1998) Testing of Composite Materials at High Rates of Strain, Advances and Challenges. Journal of Materials Processing Technology, 77, 327-336. http://dx.doi.org/10.1016/S0924-0136(97)00436-6

[17] Al-Hassani, S.T.S. and Kaddour, A.S. (1998) Strain Rate Effects on GRP, KRP and CFRP Composite Laminates. Key Engineering Materials, 141-143, 427-452. http://dx.doi.org/10.4028/www.scientific.net/KEM.141-143.427 
[18] Ochola, R.O., Marcus, K., Nurick, G.N. and Franz, T. (2004) Mechanical Behaviour of Glass and Carbon Fiber Reinforced Composites at Varying Strain Rates. Journal of Composite Structures, 63, 455-467. http://dx.doi.org/10.1016/S0263-8223(03)00194-6

[19] Hangai, Y., Kubota, N., Utsunomiya, T., Kawashima, H., Kuwazuru, O. and Yoshikawa, N. (2015) Drop Weight Impact Behavior of Functionally Graded Aluminum Foam Consisting of A1050 and A6061 Aluminum Alloys. Journal of Materials Science \& Engineering A, 639, 597-603. http://dx.doi.org/10.1016/j.msea.2015.05.007

[20] Gama, B.A., Lopatnikov, S.L. and Gillespie Jr., J.W. (2004) Hopkinson Bar Experimental Technique, a Critical Review. Applied Mechanics Reviews, 57, 223-250.

[21] Yokoyama, T., Nakai, K. and Odamura, T. (2007) High Strain-Rate Compressive Characteristics of a Unidirectional Carbon/Epoxy Composite: Effect of Loading Directions. In: Gdoutos, E.E., Ed., Experimental Analysis of Nano and Engineering Materials and Structures, Springer, Dordrecht, 681-682. http://dx.doi.org/10.1007/978-1-4020-6239-1_338

[22] Daryadel, S.S., Ray, C., Pandya, T. and Mantena, P.R. (2015) Energy Absorption of Pultruded Hybrid Glass/Graphite Epoxy Composites under High Strain-Rate SHPB Compression Loading. Materials Sciences and Applications, 6, 511518. http://dx.doi.org/10.4236/msa.2015.66054

[23] Mantena, P.R., Vangipuram, R. and Vaughan, J.G. (1994) Dynamic Flexural Properties of Pultruded Glass/Graphite Hybrid Composites. Proceedings of the 39th International SAMPE Symposium, Anaheim, 11-14 April 1994, 174-182. 